NOAA

National Marine

Fisheries Service
Fishery Bulletin



Spencer F. Baird

First U.S. Commissione of Fisheries and founder of Fishery Bulletin
Abstract-Tourism is vital to the economy of small island states like The Bahamas and is closely linked to fisheries. Fish is a protein source for tourists and residents, and both groups expect to catch and eat local fish. To adequately manage these dual demands, we need to know total removals of fish, as well as patterns of demand by tourists and residents in the past and present. Using a reconstruction approach, we performed a comprehensive accounting of fisheries catches in The Bahamas from commercial and noncommercial sectors for 1950-2010 and estimated the demand from tourism over the same period. Our results distinctly contrast with national data supplied to the Food and Agriculture Organization of the United Nations (FAO), which presents only commercial landings. Reconstructed total catches (i.e., reported catches and estimates of unreported catches) were 2.6 times the landings presented by the FAO for The Bahamas. This discrepancy was primarily due to unreported catches from the recreational and subsistence fisheries in the FAO data. We found that recreational fishing accounted for 55\% of reconstructed total catches. Furthermore, $75 \%$ of reconstructed total catches were attributable to tourist demand on fisheries. Incomplete accounting for catches attributed to the tourist industry, therefore, makes it difficult to track potentially unsustainable pressures on fisheries resources.

Manuscript submitted 19 January 2015. Manuscript accepted 3 December 2015. Fish. Bull. 114:117-131 (2016).

Online publication date: 29 December 2015. doi: 10.7755FB.114.1.10

The views and opinions expressed or implied in this article are those of the author (or authors) and do not necessarily reflect the position of the National Marine Fisheries Service, NOAA.

\title{
Unreported catch and tourist demand on local fisheries of small island states: the case of The Bahamas, 1950-2010
}

\author{
Nicola S. Smith ${ }^{1}$ \\ Dirk Zeller² \\ Email address for contact author: nicolas@sfu.ca \\ ${ }^{1}$ Earth to Ocean Research Group \\ Department of Biological Sciences \\ Simon Fraser University \\ 8888 University Drive \\ Burnaby, British Columbia, Canada V5A 1 S6 \\ 2 Sea Around Us \\ Global Fisheries Cluster \\ University of British Columbia \\ 2202 Main Mall \\ Vancouver, British Columbia, Canada V6T 1 Z4
}

Tourism is one of the largest and fastest growing industries globally (UNWTO, 2014a), and is vital to many small island developing states in which it can account for more than one-quarter of gross domestic product (GDP) (UNWTO, 2014b). In addition to its influence on island economies, tourism can have large effects on the extraction of natural resources like fisheries, particularly in the Caribbean, where visitors can greatly outnumber resident populations (Table 1, Fig. 1). Tourism, through recreational fishing and the consumption of local seafood by tourists, increases the demand on local fisheries.

Consider the case of the Commonwealth of The Bahamas, a nation of small islands, for which tourism is the primary industry, which accounted for $51 \%$ of GDP in 2003 (Sacks ${ }^{1}$ ). Located in the northern Caribbean east of Florida and northeast of Cuba,

\footnotetext{
${ }^{1}$ Sacks, A. 2006. The Bahamas total tourism economic impact: preliminary results, 8 p. Report prepared for Ministry of Tourism, The Bahamas. Global Insight Inc, Waltham, MA.
}

between $20-27^{\circ} \mathrm{N}$ and $72-79^{\circ} \mathrm{W}$, The Bahamas form an archipelago of more than 3000 low-lying islands and cays. They comprise a total land area of just under $14,000 \mathrm{~km},{ }^{2}$ and the area of its exclusive economic zone (EEZ) is more than $629,000 \mathrm{~km}^{2}$ (Fig. 2). Tourism did not become a year-round industry in The Bahamas until the 1950s, when the advent of air-conditioning in local hotels made the hotter months of the year bearable for visitors (Cleare, 2007). Since then, the total number of visitors per year has grown substantially; by 2010, visitors swelled to more than 5.3 million per year (The Bahamas Ministry of Tourism²) and outnumbered the resident population of more than 350,000 (The Bahamas Department of Statistics ${ }^{3}$ ) by an order of magnitude (Table 1, Fig. 1).

\footnotetext{
2 The Bahamas Ministry of Tourism. 2011. December 2010 preliminary revised foreign arrivals by first port of entry. [Spreadsheet available at website.]

3 The Bahamas Department of Statistics. 2010. Percentage distribution of population by island:2000 and 2010 Censuses, 1 p. [Available at website.]
} 


\section{Table 1}

Number of tourists compared with residents in 2010 for the Caribbean countries and territories where the top 10 greatest number of stopover visitors were reported that year.

\begin{tabular}{|c|c|c|c|c|c|c|}
\hline Country & $\begin{array}{l}\text { Stopover } \\
\text { visitors } \\
\left(10^{3}\right)^{1}\end{array}$ & $\begin{array}{l}\text { Cruise } \\
\text { visitors } \\
\left(10^{3}\right)^{1}\end{array}$ & $\begin{array}{l}\text { Total } \\
\text { visitors } \\
\left(10^{3}\right)\end{array}$ & $\begin{array}{l}\text { Resident } \\
\text { population } \\
\quad\left(10^{3}\right)^{1}\end{array}$ & $\begin{array}{c}\text { Stopover } \\
\text { visitors as } \\
\% \text { of resident } \\
\text { population }\end{array}$ & $\begin{array}{c}\text { Mean length } \\
\text { of stay for } \\
\text { stopover visitors } \\
{\text { (nights) }{ }^{1}}^{1}\end{array}$ \\
\hline Aruba & 824 & 569 & 1394 & 108 & 763 & 7.8 \\
\hline Bahamas & 1370 & 3810 & 5180 & 347 & 395 & 6.8 \\
\hline Barbados & 532 & 665 & 1197 & 275 & 194 & 9.8 \\
\hline Cuba & 2532 & unavailable & unavailable & 11,242 & 23 & 10.9 \\
\hline Dominican Republic & 4125 & 353 & 4477 & 9974 & 41 & 9.2 \\
\hline Jamaica & 1922 & 910 & 2831 & 2702 & 71 & 9.0 \\
\hline Martinique & 476 & 75 & 551 & 400 & 119 & 13.3 \\
\hline Puerto Rico & 1369 & 1191 & 2560 & 3979 & 34 & 2.6 \\
\hline St. Maarten & 443 & 1513 & 1956 & 37 & 1198 & unavailable \\
\hline U.S. Virgin Islands & 691 & 1859 & 2550 & 110 & 628 & unavailable \\
\hline
\end{tabular}

${ }^{1}$ Source: Caribbean Tourism Organization.

The combined demand for local fishes in The Bahamas by a burgeoning tourist industry and a growing resident population raises an important question: can domestic fisheries keep up with the current patterns of fishing and seafood consumption of both groups in the long term? To address this question, comprehensive statistics on total removals from commercial and noncommercial fishing sectors and on patterns of local demand on fisheries by tourists and residents are fundamental, as are assessments of the status of stocks of the main target species. The government of The Bahamas, however, currently lacks the financial resources and technical expertise needed to adequately assess fish stocks $\left(\mathrm{CFU}^{4}\right)$, and it does not track the local demand on fisheries by either residents or tourists. Similarly, although some national statistics exist for commercial landings, catch from other important noncommercial sectors, like recreational fishing, are ignored.

Fisheries in The Bahamas, like most tropical nearshore fisheries of the Caribbean, western Pacific, and Southeast Asia, are data poor in that they lack conventional, "scientific" data (e.g., on stock age structure, natural and fishing mortality, catch per unit of effort over time) or lack rigorous analyses of reliable data (Johannes, 1998; Bentley and Stokes, 2009). In such instances, a variety of alternative approaches to traditional stock assessment have been used to develop reference points for management-methods that include sequential trends analysis (e.g., depletion-corrected average catch [DCAC], MacCall, 2009; cumulative sum [CUSUM], Manly and Mackenzie, 2000), vulnerability analysis (e.g., productivity-susceptibility analysis of

\footnotetext{
${ }^{4}$ CFU (CARICOM Fisheries Unit). 2001. Report of the multidisciplinary survey of the fisheries of the Bahamas, $43 \mathrm{p}$. CFU, Belize City, Belize. [Available at website.]
}

vulnerability [PSA], Field et al., 2010), and extrapolation (e.g., Robin Hood approach, Smith et al., 2009).

These methods for analysis of data-poor fisheries often overlap, are complementary, or are nested within other methods. Moreover, these methods differ in their requirements for the quality and quantity of data and, therefore, involve varying degrees of uncertainty and require precautionary buffers (Honey et al., 2010). For example, a variety of techniques are used in sequential trends analysis to detect trends and infer changes in fish populations or stocks from available time-series data, whereas extrapolation methods, such as the Robin Hood approach, are used when virtually no conventional, scientific data are available. For the latter analyses, the local knowledge of fishermen and other resource users are used, as well as the information inferred from assumptions based on data-rich fisheries (Honey et al., 2010).

In this study, we used the recent, globally established catch reconstruction approach of Zeller et al. (2007, 2015) for data-limited fisheries, a method that also has been used successfully in nontropical areas (e.g., Zeller et al., 2011a, 2011b), to retroactively estimate a time series of commercial and noncommercial marine fisheries catches for The Bahamas during 1950-2010. We chose the year 1950 as our starting point because it is the first year for which data were available in the global landings database of the FAO. Another objective of this study was to estimate local demand on fisheries by the tourist industry over the same period. As described previously, tourism is the primary industry in The Bahamas and is closely linked to fisheries. To better understand historical trends in fisheries catches (and predict future trends), we must view these patterns in light of changes in tourist demand on local fisheries. 




\section{Materials and methods}

\section{Reconstruction of marine fisheries catches}

Reconstruction of fisheries catches is an approach to retroactively estimate catches when reliable time-series data are lacking (Zeller et al., 2007, 2015). In some instances, this approach has involved interpolations, cautious extrapolation, and assumptions based on local expert opinion in lieu of quantitative data. The use of interpolations, extrapolation, and assumptions has resulted in potentially higher uncertainty in some of the data provided here (see also Zeller et al., 2011a, 2015), but this approach is justifiable because of the unacceptable alternative, namely that catches for missing sectors, taxa, or time periods would be interpreted as zero catches-an outcome that has serious consequences for effective management and conservation (Pauly, 1998).
The catch reconstruction approach used here consists of 7 general steps (Zeller et al., 2007, 2015):

1. Identification of existing time-series data on catches to validate the quality of data transfer from national (e.g., annual reports from the Bahamas Department of Marine Resources, previously named the Department of Fisheries) to international (e.g., FAO reported landings data by FAO area, taxon, and year) levels.

2. Identification of sectors, time periods, taxa, etc. not covered by step 1 through literature searches and local expert consultations.

3. Search for available information sources to serve as alternatives to missing catch data identified in step 2 , through comprehensive literature searches and local expert consultations. In this step, we look for any source of information, including case studies, health studies, household surveys, technical reports, data sets, and expert opinion.

4. Development of data anchor points in time for missing segments based on data and information sources discovered in step 3, and expansion of them to countrywide catch estimates for each sector or taxa by using clearly stated and conservative assumptions.

5. Application of interpolation for time periods between data anchor points for each fishing sector or taxa, either linearly or on the basis of assumptions for commercial sectors, and application of interpolation, typically through per capita catch rates for noncommercial sectors, taking into account major political, socioeconomic, and environmental impacts.

6. Estimation of final time series of total catch by combining reported catches (identified in step 1) and interpolated, country-expanded, missing data segments (produced in step 5). The final data series shows catch by fisheries sector, taxon, and year. We define fisheries sectors using country- or regionalspecific definitions: large-scale commercial, artisanal (small-scale commercial), subsistence (smallscale noncommercial), and recreational (small-scale noncommercial)

7. Expression of the level of uncertainty in the data and information sources and in the assumptions made during reconstruction, by fishing sectors and time periods of the reconstruction. This final step is based on "scoring" criteria inspired by the Intergovernmental Panel on Climate Change (Mastrandrea et al., 2010; Table 2). Because the senior author of 


\section{Table 2}

Score used for evaluating the quality of the time series of reconstructed catches, with their range of uncertainty (Intergovernmental Panel on Climate Change [IPCC] criteria from Figure 1 of Mastrandrea et al. [2010]).

\begin{tabular}{|c|c|c|c|c|}
\hline \multicolumn{4}{|c|}{ Range of uncertainty } & \multirow[b]{2}{*}{ Corresponding IPCC criteria } \\
\hline & & $-\%$ & $+\%$ & \\
\hline 4 & Very high & 10 & 20 & $\begin{array}{l}\text { High agreement between multiple sources for the same data and robust evi- } \\
\text { dence of data accuracy }\end{array}$ \\
\hline 3 & High & 20 & 30 & $\begin{array}{l}\text { High agreement between multiple sources for the same data and medium evi- } \\
\text { dence of data accuracy, or medium agreement between multiple sources for } \\
\text { the same data and robust evidence of data accuracy }\end{array}$ \\
\hline 2 & Low & 30 & 50 & $\begin{array}{l}\text { High agreement between multiple sources for the same data and limited evi- } \\
\text { dence of data accuracy, or medium agreement between multiple sources for } \\
\text { the same data and medium evidence of data accuracy, or low agreement } \\
\text { between multiple sources for the same data and robust evidence of data } \\
\text { accuracy }\end{array}$ \\
\hline 1 & Very low & 50 & 90 & $\begin{array}{l}\text { Low agreement between multiple sources for the same data and low evidence } \\
\text { of data accuracy }\end{array}$ \\
\hline
\end{tabular}

the study described here was most familiar with the data and information sources used, she reviewed the underlying data and assumptions of the reconstruction, by fishing sectors and by 3 time periods, and assigned relative uncertainty scores, by sector and time period. Scores were then catch-weighted by sector to derive average upper and lower ranges of uncertainty for each of 3 time periods (Table 3): early (1950-1969), mid (1970-1989) and late (1990-2010). Note that scoring does not reflect the method of reconstruction but actually the relative "trustworthiness" of the data and information sources per sector and time period.

Details on these steps in general and as they were applied specifically to The Bahamas are provided in Zeller et al. (2015) and Smith and Zeller5, respectively. Here, we summarize the major information and data sources, approaches, and assumptions involved in estimating catches from 3 sectors: 1) commercial fisheries, which is further subdivided into the artisanal fishery and the large-scale fishery for Caribbean spiny lobster (Panulirus argus); 2) subsistence fishery; and 3) recreational fishery. We also estimated the demand on fisheries from the tourist industry for the period 1950-2010. It is of key importance for readers to understand that we aim to address and improve the accuracy of catch data, and not the precision of the estimates, as we attempt to address an inherent negative bias in reported data (i.e., the result of the absence of data, and hence effective substitution with a zero, for catches taken by sectors, such as recreational fisheries, that are not part

\footnotetext{
${ }^{5}$ Smith, N. S., and D. Zeller. 2013. Bahamas catch reconstruction: fisheries trends in a tourism-driven economy (1950-2010), 28 p. Fisheries Centre Working Paper \#201308. Univ. British Columbia, Vancouver, Canada. [Available at website.]
}

of the current data monitoring system; see also Covey, 2000).

\section{Commercial fishery}

The Bahamas provide national data on only commercial (i.e., both artisanal and large-scale Caribbean spiny lobster) landings to FAO (Braynen ${ }^{6}$ ). We compared available national statistics (based on data from annual reports published by colonial and national governments of The Bahamas[HMSO$\left.{ }^{7}, \mathrm{BDF}^{8}\right]$ ) with

\footnotetext{
${ }^{6}$ Braynen, M. 2011. Personal commun. The Bahamas Department of Marine Resources, Nassau, The Bahamas 3028.

7 HMSO (Her Majesty's Stationery Office). 1952. Report for The Bahama Islands, 1950-1951, 42 p. Colonial Annual Reports. Colonial Office, HMSO, London.

HMSO (Her Majesty's Stationery Office). 1955. Report for The Bahama Islands, 1952-1953, 48 p. Colonial Annual Reports. Colonial Office, HMSO, London.

HMSO (Her Majesty's Stationery Office). 1957. Report for The Bahama Islands, 1954-1955, 50 p. Colonial Annual Reports. Colonial Office, HMSO, London.

HMSO (Her Majesty's Stationery Office). 1959. Report for The Bahama Islands, 1956-1957, 64 p. Colonial Annual Reports. Colonial Office, HMSO, London.

HMSO (Her Majesty's Stationery Office). 1961. Report for The Bahama Islands, 1958-1959, 70 p. Colonial Annual Reports. Colonial Office, HMSO, London.

HMSO (Her Majesty's Stationery Office). 1963. Report for The Bahama Islands, 1960-1961, 75 p. Colonial Annual Reports. Colonial Office, HMSO, London

8 BDF (Bahamas Department of Fisheries). 1990. Annual Report 1990, 85 p. BDF, Nassau, The Bahamas.

BDF (Bahamas Department of Fisheries). 1991. Annual Report 1991, 130 p. BDF, Nassau, The Bahamas.

BDF (Bahamas Department of Fisheries). 1992. Annual Report 1992, 85 p. BDF, Nassau, The Bahamas.

BDF (Bahamas Department of Fisheries). 1993. Annual Report 1993, 116 p. BDF, Nassau, The Bahamas.

BDF (Bahamas Department of Fisheries). 1996. Annual
} Report 1996, 35 p. BDF, Nassau, The Bahamas. 


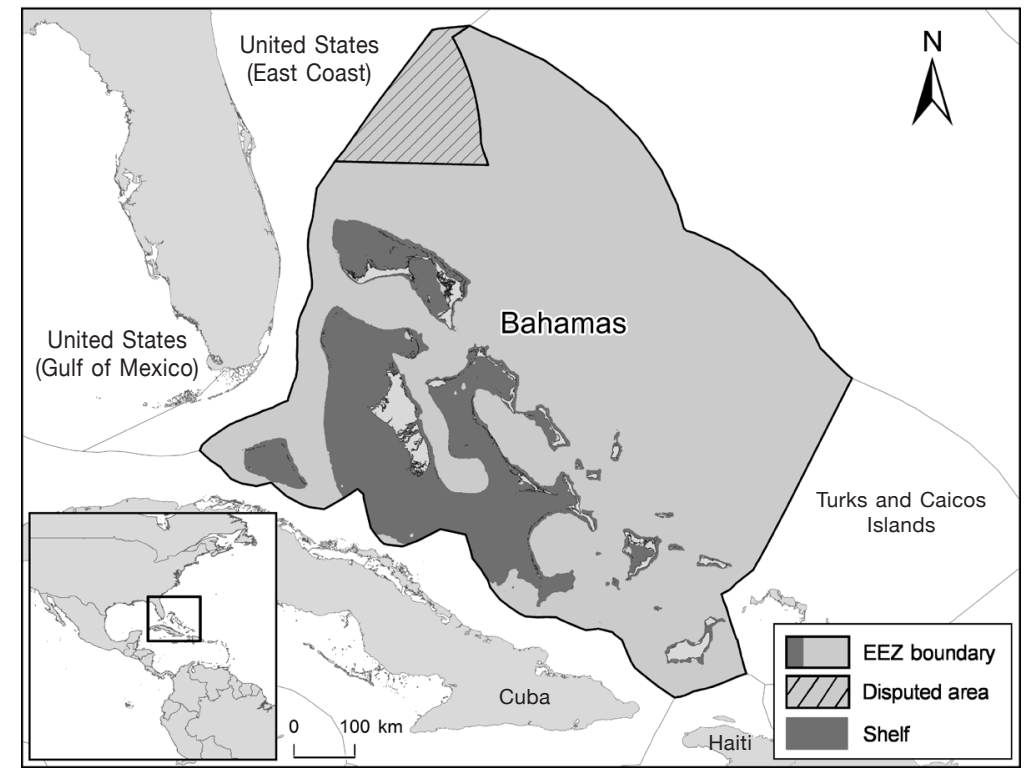

Figure 2

Map of the Commonwealth of The Bahamas showing the exclusive economic zone (EEZ), which has an area of more than $629,000 \mathrm{~km}^{2}$, and shelf areas (to a depth of $200 \mathrm{~m}$ ) that cover more than $108,000 \mathrm{~km}^{2}$.

FAO data that we accessed through the FAO application FishStatJ (Capture Production data set, available at website), and we concluded that there was a good transfer of data from the national to the international level for the postcolonial period (i.e., 1970-2010). We, therefore, used FAO data as the basis for further calculations for 1970-2010. National commercial landings from 1970 to 2010, however, were systematically underreported because they were based on the sampling of a subset of landing sites (i.e., sites where commercial fishing boats "land" or dock) and there was no attempt to expand the data set to include sites that were not sampled $\left(\right.$ Braynen $\left.^{6}\right)$. Given that the total number of landing sites in The Bahamas is unknown, we relied on local expert opinion from staff of The Bahamas Department of Marine Resources regarding the fraction of commercial catch for each taxon that was likely not to be reported. We then retroactively adjusted FAO data from 1970 to 2010 to account for countrywide, unreported commercial landings (Braynen ${ }^{6}$; Table 4).

We concluded that FAO data on capture tonnage are underestimates of the actual tonnage of commercial catches during the colonial period because FAO data did not closely match national (colonial) statistics for the period 1950-1969. Colonial statistics for these years consisted almost entirely of domestic catches that were exported. For example, FAO reports a total catch of 600 metric tons (t) in 1950, but a Colonial Annual Report for The Bahamas states that more than twice that amount (i.e., 1381 t) was exported as Caribbean spiny lobster alone in that year (HMSO, report 1950 $1952^{7}$ ). To address the problem of underreported commercial catches, we calculated the average per capita commercial catch rate for the years 1970-1975 (on the basis of our expanded, countrywide commercial catch estimates) and applied this catch rate to the human population census data for 1950-1969. Our method resulted in an estimate of total commercial catch for the colonial period that was $11 \%$ higher than the level reported in the FAO data. We acknowledge that per capita commercial catch rates likely were greater in 1970-1975 than in 1950-1969; however, our estimates for earlier time periods are still conservative because our assessment of total commercial catches in 1950 (i.e., $1221 \mathrm{t}$ ) was less than the level reported for exports of Caribbean spiny lobster alone.

To determine the taxonomic composition of the commercial catches for 1950-2010, we combined FAO data with statistics from the annual reports published by the national government and with expert opinion of staff from the Department of Marine Resources (for details, see Smith and Zeller5).

\section{Subsistence fishery}

We are unaware of any written reports that quantify the extent of subsistence fishing in The Bahamas. Therefore, we relied on 2 sources to estimate catch from this sector: 1) resident population data and 2) expert opinion of staff of the Department of Marine Resources (Table 4).

Using the groupings and definitions used in The Bahamas, we divided the islands of The Bahamas into 1) the more developed islands of New Providence and Grand Bahama and 2) the remaining, less developed islands, which are referred to collectively as the "Family 
Table 3

Fisheries sectors and associated ranges of uncertainty for reconstruction of catches in The Bahamas for 3 time periods. We divided catch into 3 sectors: 1) commercial fisheries, which was further subdivided into the artisanal fishery and the large-scale fishery for Caribbean spiny lobster (Panulirus argus), 2) the recreational fishery, defined as small-scale noncommercial fishing that is primarily for recreation and in which catch is not sold or bartered and, 3) subsistence fishery, defined as small-scale noncommercial fishing in which catch does not enter the formal market but is taken home and consumed by fishermen and their families or is locally bartered.

\begin{tabular}{lcccc}
\hline & & & \multicolumn{2}{c}{ Uncertainty range } \\
Sector & Years & Score & $-\%$ & $+\%$ \\
\hline Artisanal & $1950-1969$ & 3 & 20 & 30 \\
Artisanal & $1970-1989$ & 4 & 10 & 20 \\
Artisanal & $1990-2010$ & 4 & 10 & 20 \\
Large-scale Caribbean spiny lobster & $1950-1969$ & 2 & 30 & 50 \\
Large-scale Caribbean spiny lobster & $1970-1989$ & 4 & 10 & 20 \\
Large-scale Caribbean spiny lobster & $1990-2010$ & 4 & 10 & 20 \\
Recreational & $1950-1969$ & 1 & 50 & 90 \\
Recreational & $1970-1989$ & 2 & 30 & 50 \\
Recreational & $1990-2010$ & 3 & 20 & 30 \\
Subsistence & $1950-1969$ & 1 & 50 & 90 \\
Subsistence & $1970-1989$ & 1 & 50 & 90 \\
Subsistence & $1990-2010$ & 1 & 50 & 90 \\
& & & & \\
\hline
\end{tabular}

Islands." Few economic opportunities existed for most Bahamians during 1950-1969, particularly in the less developed Family Islands. On the basis of local expert opinion, we assumed that, for the period 1950-1969, $40 \%$ of the residents of the Family Islands ate per week the equivalent in weight of 2 plate-size snappers (i.e., $\sim 32.55 \mathrm{~kg} \cdot$ person $^{-1} \cdot$ year $^{-1}$ ) obtained from subsistence fishing and that $10 \%$ of residents of the more developed islands of New Providence and Grand Bahama ate per week the equivalent in weight of 1 plate-size snapper (i.e., $16.29 \mathrm{~kg} \cdot$ person $^{-1} \cdot$ year $^{-1}$ ) obtained through subsistence fishing (Braynen ${ }^{6}$ ).

Following the beginning of the political rule of the black majority in 1967 and of independence from Britain in 1973, economic opportunities increased considerably for most Bahamians; hence, their reliance on subsistence fisheries was expected to have decreased. On the basis of local expert opinion, we assumed that throughout the 1970s the number of people dependent on subsistence fisheries steadily decreased so that, by 1980-2010, only $20 \%$ of residents of the Family Islands had a subsistence catch rate of $32.55 \mathrm{~kg} \cdot$ person $^{-1} \cdot$ year $^{-1}$ and $5 \%$ of the residents of New Providence and Grand Bahama had a subsistence catch rate of 16.29 $\mathrm{kg} \cdot$ person $^{-1} \cdot$ year $^{-1}$ (Braynen 6 ).

We are unaware of any published subsistence catch rates for other Caribbean countries that are based on empirical data. However, our estimates are comparable to fresh seafood consumption rates determined from household surveys for Anguilla (26.2 kg.person-1.year-1) $\left(\right.$ Jones $^{9}$ ) and for the Turks and Caicos Islands, where

9 Jones, T. P. 1985. The fishing industry of Anguilla 1985,
$97 \%$ of households ate fish at least once per week, $79 \%$ ate queen conch (Strombus gigas) more than once per week, and $46 \%$ of households consumed Caribbean spiny lobster more than once per week (Maitland, 2006).

To determine the taxonomic composition of subsistence catches throughout the time series, we assumed the same species composition and relative species proportions as those of the commercial shallow-water fisheries. However, we excluded deepwater finfishes, sharks, crabs, and sea cucumbers from subsistence composition (Smith and Zeller ${ }^{5}$ ).

\section{Recreational fishery}

We divided recreational catches into 2 categories: 1 ) fish that were caught during major tournaments and 2) fish that were caught for recreation outside of tournaments (Table 4).

The United States Recreational Billfish Survey (RBS) program recorded total billfish catches (in numbers) and effort data from major fishing tournaments in several parts of the Atlantic, including in The Bahamas during 1972-2007. Data from the RBS also include the fate of fish that were caught (i.e., retained, released, or tagged and released [Diaz et al., 2007]). We used data directly from the RBS program to determine the quantity of blue marlin (Makaira nigricans), white marlin (Kajikia albida), and sailfish (Istiophorus platypterus) that were retained during tournaments during 1972-

38 p. A report prepared for the Anguillan government and Commonwealth Secretariat, Anguilla. 


\section{Table 4}

Data sources, assumptions, and parameters used for reconstruction of catches in The Bahamas for the period 1950-2010. The FAO data used for this study came from the Capture Production data set accessed through the FAO application FishStatJ.

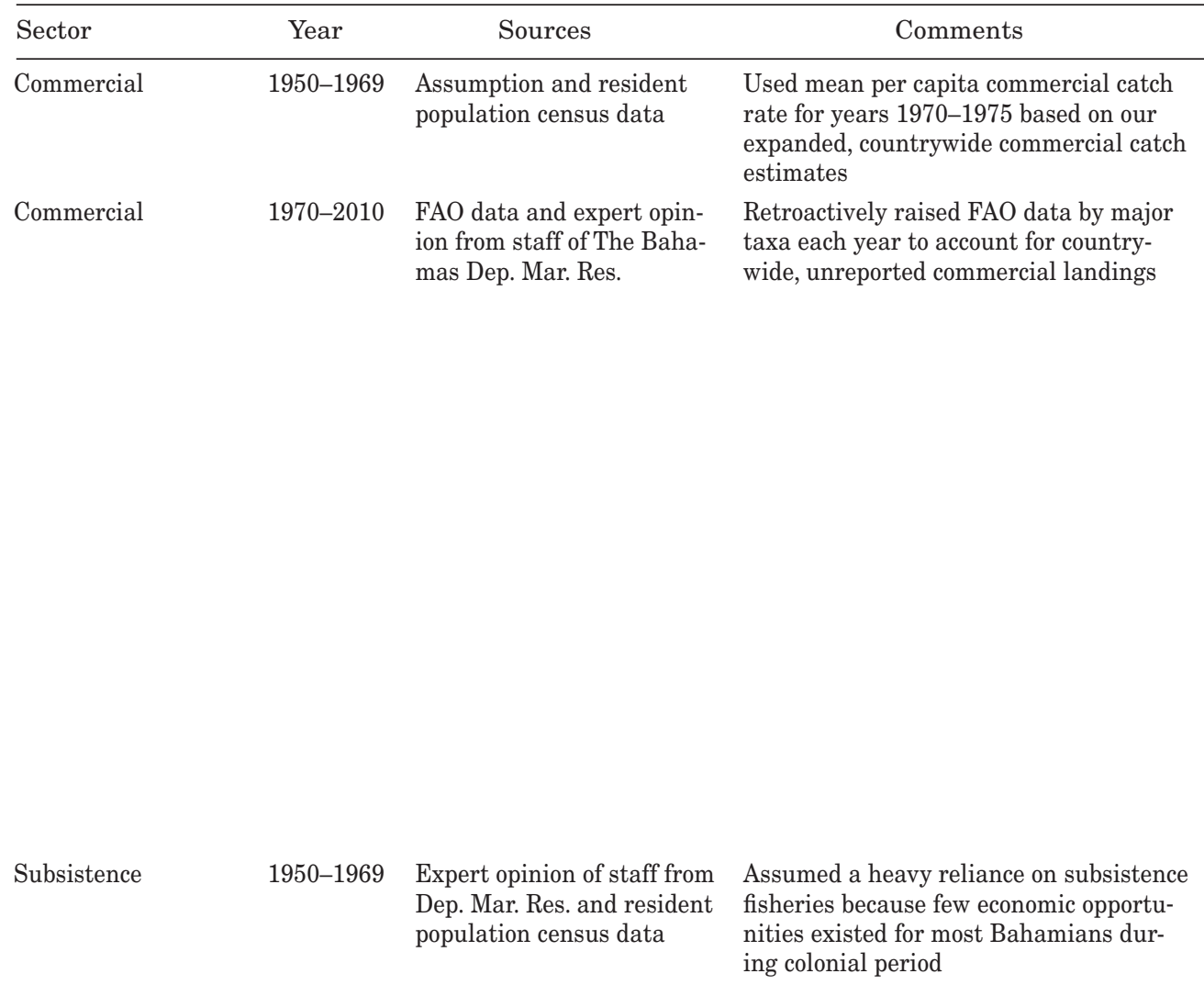
ing colonial period

Subsistence

1970-1979 Assumption

Subsistence

1980-2010 Expert opinion from staff of the Dep. Mar. Res. and resident population census data

Recreational (billfish catch from major tournaments)
1950 Assumption based on data from the U.S. Recreational Billfish Survey (RBS) program
Linearly interpolated total annual catch by residents of the Family Islands and of New Providence and Grand Bahamas between 1969 and 1980 .

Assumed reliance on subsistence fisheries decreased after the beginning of black majority political rule in 1967 and independence from Britain in 1973. Assumed that the per capita subsistence catch rate was the same as the rate in 1950-1969 but that the percentage of people dependent on subsistence fisheries decreased by $50 \%$ for residents of the Family Islands and of New Providence and Grand Bahama.

There were fewer tournaments in 1950 than in 1972, which is the first year of RBS data for The Bahamas. Assumed that total catches in 1950 were half that of 1972 .
Haemulon spp. $=1.1$ times FAO data

Jacks $($ Carangidae $)=1.15$ times FAO data

Nassau grouper (Epinephelus striatus ) $=1.1$ times FAO data

Other groupers (Epinephelidae) $=1.1$ times FAO data Misc. marine fishes $=1.15$ times FAO data

Queen conch (Strombus gigas $)=1.15$ times FAO data Sharks=1.05 times FAO data Snappers $($ Lutjanidae $)=1.15$ times FAO data Caribbean spiny lobster (Panulirus argus) $=1.05$ times FAO data

Florida stone crab (Menippe mercenaria $)=1.03$ times FAO data

Per capita subsistence catch rate of 32.55 $\mathrm{kg} \cdot$ person $^{-1}$.year $^{-1}$ for $40 \%$ of residents of the Family Islands

Per capita subsistence catch rate of 16.29 $\mathrm{kg} \cdot$ person $^{-1}$. year ${ }^{-1}$ for $10 \%$ of residents of the more developed islands of New Providence and Grand Bahama

Total annual subsistence catch declined by $27 \mathrm{t} /$ year for the Family Islands and by $7 \mathrm{t} /$ year for New Providence and Grand Bahama

Per capita subsistence catch rate of 32.55 $\mathrm{kg} \cdot$ person $^{-1}$ year $^{-1}$ for $20 \%$ of residents of the Family Islands

Per capita subsistence catch rate of 16.29 $\mathrm{kg} \cdot$ person $^{-1} \cdot$ year $^{-1}$ for $5 \%$ of residents of more developed islands of New Providence and Grand Bahama

Total catch was 3.65 t/year

Table continued 
Table 4 (continued)

\begin{tabular}{lccl}
\hline Sector & Year & Sources & Comments \\
\hline $\begin{array}{l}\text { Recreational (billfish } \\
\text { catch from major }\end{array}$ & $1951-1971$ & Assumption & $\begin{array}{l}\text { Linearly interpolated total tournament } \\
\text { catches for 1951-1971. }\end{array}$
\end{tabular}

catch from major

tournaments)

Recreational (billfish catch from major tournaments)

Recreational (billfish catch from major tournaments)

Recreational (catch outside of tournaments-tourists)

Recreational (catch outside of tournaments-tourists)

Recreational (catch outside of tournaments-tourists)

Recreational (catch outside of tournaments_residents)

Recreational (catch outside of tournaments—residents)

1972-2006 Data from the RBS program Used data directly from the RBS program

2007-2010 Assumption based on data from the RBS program

1950-1985 Assumption based on visitor arrival data, 1980 visitor activities survey report and 1986 recreational fishing regulations for visitors to The Bahamas

1986-2006 Visitor arrival data, 1980 visitor activities survey report, and recreational fishing regulations for visitors to The Bahamas

2007-2010 Assumption based on visitor arrival data, 1980 visitor activities survey report, and 1986 recreational fishing regulations for visitors to The Bahamas

1950-1969 Expert opinion from staff of the Dep. Mar. Res., resident population census data, and 1986 recreational fishing regulations for visitors

1970-2010 Expert opinion from staff of the Dep. Mar. Res., resident population census data, and recreational fishing regulations for visitors
Organizers stopped reporting catches to the RBS program after 2007, and incomplete reporting likely occurred in 2007. Used mean annual catch for the years 2000-2006 for remainder of time series

Prior to 1986, there were no maximum catch limits for recreational fishing. Assumed that visitors retained twice as much as the maximum per capita catch limits stipulated in the 1986 legislation

Catch rate represents $80 \%$ of the per capita allowable catch limit. Assumed that visitors adhered to the catch limits

Recreational fishing legislation revised with the aim of reducing total annual catch by $50 \%$. Catch rate represents $50 \%$ of the per capita allowable catch limit based on 1986 legislation. Assumed that visitors adhered to the catch limits

Assumed that $0.5 \%$ of residents of the Family Islands fished for recreation 6 times a year and $1 \%$ of residents of New Providence and Grand Bahama fished for recreation 4 times a year. For each trip, we assumed that residents caught $50 \%$ of the 1986 maximum per capita catch limits for visitors (i.e., 34 $\mathrm{kg} \cdot$ fisherman ${ }^{-1}$.trip $^{-1}$ )

Assumed that recreational fishing increased with increasing economic opportunities, particularly for residents of New Providence and Grand Bahama. Assumed that both the percentage of residents that fished for recreation and the frequency of recreational fishing doubled for residents of New Providence and Grand Bahama.

Hence, $2 \%$ of residents of New Providence and Grand Bahama fished for recreation 8 times a year.

Assumed that the percentage of residents of the Family Islands that fished for recreation did not change during 1950-1969 (i.e., $0.5 \%$ ) but that the frequency with which they fished doubled to 12 times a year.

For each trip, we assumed that residents of the Family Islands and of New Providence and Grand Bahama caught $50 \%$ of the 1986 maximum per capita catch limits for visitors (i.e., $34 \mathrm{~kg}$ ·fisherman ${ }^{-1} \cdot$ trip $^{-1}$ ).
Contact the NOAA Southeast Fisheries Science Center for details

Total catch of $6.08 \mathrm{t}$ tyear

Per capita recreational catch rate of $136 \mathrm{~kg} \cdot$ person $^{-1}$. visit $^{-1}$

Per capita recreational catch rate of $54 \mathrm{~kg} \cdot$ person $^{-1}$.visit $^{-1}$

Per capita recreational catch rate of $34 \mathrm{~kg} \cdot$ person $^{-1}$. visit $^{-1}$

Recreational catch rate of $204 \mathrm{~kg} \cdot$ fisherman $^{-1} \cdot \mathrm{year}^{-1}$ for residents of the Family Islands and 136 $\mathrm{kg} \cdot$ fisherman ${ }^{-1}$.year ${ }^{-1}$ for residents of New Providence and Grand Bahama

Recreational catch rate of $408 \mathrm{~kg} \cdot$ fisherman $^{-1} \mathrm{year}^{-1}$ for $0.5 \%$ of residents of the Family Islands and 272 $\mathrm{kg}$.fisherman ${ }^{-1}$. year $^{-1}$ for $2 \%$ of residents of New Providence and Grand Bahama 
2006 (Table 4). Before 1972, data for The Bahamas were not collected during the RBS program, and there were also fewer tournaments and, therefore, presumably, lower total tournament catches (Cleare, 2007). Hence, we assumed that billfish catches in 1950 were half those in 1972, and we linearly interpolated catches for 1951-1971 (Table 4). In 2007, the quality of the tournament catch data that was reported to the RBS program was likely to have deteriorated; after 2007 organizers stopped reporting catches for The Bahamas to the RBS program altogether (Venizelos ${ }^{10}$ ). We, therefore, calculated mean annual tournament catch for the years 2000-2006 and held this value constant for the remainder of the time series, although this calculation could have resulted in an underestimate (Table 4).

It is important to note that other pelagic species, such as dolphinfish (Coryphaena hippurus), wahoo (Acanthocybium solandri), and tunas, are also caught during tournaments. We did not, however, have access to any data or information on the quantities of nonbillfish species that were retained during tournaments. Therefore, our estimate of total retained catch during tournaments is limited to billfish species and is highly conservative.

To estimate catches outside of tournaments, we separated data into 2 categories: 1) fish caught by visitors and 2) fish caught by residents.

We relied on 3 information sources to reconstruct visitor catches: 1 ) visitor arrival data; 2) the Ministry of Tourism visitor activities survey report; and 3) recreational fishing regulations for visitors to The Bahamas (Table 4). We estimated recreational catch of visitors by combining data on the number of visitors per year with the proportion of visitors that indicated that they fished during their stay (values were based on the Ministry of Tourism 1980 visitor activity survey report, as presented in Thompson [1989]), along with per capita maximum allowable catch for demersal and pelagic species, as stipulated in the Fisheries Resources (Jurisdiction and Conservation) Regulations of 1986 [available at website]. We estimated a per capita recreational catch rate of $54 \mathrm{~kg} \cdot$ person $^{-1}$.visit $^{-1}$ during $1986-2006$. This catch rate was determined with the assumption that the proportion of visitors that fished during their stay remained constant during 1986-2006 (i.e., 6.2\%, $5.3 \%$, and $20.0 \%$ of stopover visitors to New Providence, Grand Bahama, and the Family Islands, respectively), and this rate represents $80 \%$ of the per capita allowable catch for key taxa. This catch rate is conservative given that the number of visitors who have fished in The Bahamas during their stay has increased in recent times and given that catches by visitors to The Bahamas were often thought to exceed maximum catch limits (Cox et al., 2005).

Before 1986, there were no maximum catch limits for recreational fishing in The Bahamas. Moreover, during this period many visitors exploited this lack of

${ }^{10}$ Venizelos, A. 2012. Personal commun. Southeast Fish. Sci. Cent., Natl. Mar. Fish. Serv., NOAA, Miami, FL 33149. regulation by actually fishing commercially (Thompson, 1989). We, therefore, assumed (on the basis of the number of stopover visitors per year and the visitor activity survey report) that, during 1950-1985, visitors who fished in The Bahamas during their stay caught and retained twice as much as the maximum per capita catch limits stipulated for key taxa in the 1986 legislation (i.e., $~ 136 \mathrm{~kg} \cdot$ person $^{-1}$ visit $^{-1}$ ). In 2007, the government of The Bahamas revised the maximum catch limits for key taxa with the aim of reducing total catch. The government assumed that this revision would result in a 50\% reduction in catches from the catch rate observed in 1986 (Braynen ${ }^{6}$ ). In the absence of better data, we accepted this assumption and applied a recreational per capita catch rate of $34 \mathrm{~kg} \cdot$ person $^{-1}$. visit ${ }^{-1}$, estimating that visitors caught $50 \%$ of the 1986 catch limits for key taxa (Table 4).

Much less is known about the regular recreational fishing habits of residents. Unlike the existence of legislation for visitors, there is currently no legislation that limits the quantity of fish that may be caught by residents for recreational purposes. Therefore, we relied on 3 sources to estimate catch for this component: 1) resident population data; 2) expert opinion of staff from the Department of Marine Resources; and 3) The Bahamas recreational fishing regulations for visitors (Table 4). We assumed that, during $1950-1969,0.5 \%$ of residents of the Family Islands fished for recreation 6 times a year and $1 \%$ of residents of New Providence and Grand Bahama fished recreationally 4 times a year $\left(\right.$ Braynen $\left.^{6}\right)$. For each trip, it was assumed that residents caught $50 \%$ of the 1986 maximum per capita catch limits for key taxa for visitors (i.e., $34 \mathrm{~kg}$. person ${ }^{-1}$.trip ${ }^{-1}$ ). This assumption amounts to an annual recreational catch rate of 204 $\mathrm{kg}$.fisherman ${ }^{-1}$.year ${ }^{-1}$ and $136 \mathrm{~kg} \cdot$ fisherman ${ }^{-1}$. year $^{-1}$ for Family Islanders and residents of New Providence and Grand Bahama, respectively.

With increasing economic opportunities in the 1970s, recreational fishing is also likely to have increased, particularly on New Providence and Grand Bahama. According to expert opinion from staff of the Department of Marine Resources (Braynen ${ }^{6}$ ), during 1970-2010, 2\% of residents of New Providence and Grand Bahama fished for recreation 8 times a year. By comparison, although the proportion of residents fishing recreationally in the Family Islands did not change, the frequency with which they fished increased. Hence, it was assumed that during 1970-2010, 0.5\% of Family Islanders fished for recreation once a month. A catch rate of $34 \mathrm{~kg} \cdot$ person $^{-1} \cdot$ trip $^{-1}$ translates to annual catches of $272 \mathrm{~kg} \cdot$ fisherman ${ }^{-1} \cdot$ year $^{-1}$ for residents of New Providence and Grand Bahama and to a rate of $408 \mathrm{~kg}$.fisherman ${ }^{-1}$.year ${ }^{-1}$ for residents of the Family Islands.

To determine the taxonomic composition for recreational catches from tournaments, we relied on information from the RBS program; for catches outside of tournaments, we relied on 3 sources: 1) recreational fishing regulations; 2) Thompson (1989); and 3) demersal catch composition from commercial fisheries (for details, see Smith and Zeller ${ }^{5}$ ). 


\section{Use of expert opinion in reconstruction of fisheries catch data}

An expert is someone who possesses knowledge about a given topic through training, research, practicing of skills, or personal experience (Burgman et al., 2011). Elicitation of expert opinion has been used for a variety of environmental issues, including conservation (e.g., Murray et al., 2009), invasive species management (e.g., Kuhnert, 2011), climate change impacts (e.g., Morgan et al., 2001), and models of managed systems, such as logged forests (e.g., Crome et al., 1996) and data-limited fisheries (e.g., Griffiths et al., 2007). Many of the parameters in our reconstruction are derived from the opinion of a single expert (i.e., M. Braynen, Director of the Department of Marine Resources) because of limited empirical data (Table 4). Nevertheless, we followed the 5 general steps described by Martin et al. (2012) to elicit expert knowledge:

1. Decide how information will be used;

2. Determine what to elicit;

3. Design the process for eliciting information;

4. Execute the process for eliciting information; and

5. Translate the information for use in a model.

We elicited expert information both directly and indirectly for use in our catch reconstruction. Direct elicitation of information involved posing questions that would provide quantitative responses that could be used directly in the reconstruction. For example, we asked: What percentage of commercial catch of Caribbean spiny lobster do you think is unreported?

In contrast, indirect elicitation of information involved posing questions that resulted in responses that were subsequently converted to quantitative values for use in our reconstruction. For example, to come up with the estimate for the subsistence catch rate of 32.55 $\mathrm{kg} \cdot$ person $^{-1}$.year ${ }^{-1}$ for $40 \%$ of residents of the Family Islands during 1950-1969, we asked 2 questions: 1) what percentage of residents of the Family Islands do you think relied on subsistence fishing for at least part of their dietary requirements from 1950 through 1969? and 2) Given your answer to question 1, if we estimated the amount of seafood obtained through subsistence fishing from 1950 through 1969 in terms of the number of plate-sized snappers consumed per person per week, how many plate-size snappers per person per week do you think were obtained by subsistence fishing in the Family Islands?

In all instances, information was elicited through one-on-one interviews with the expert either in person or over the telephone. It should be noted, however, that we did not directly elicit an estimate of uncertainty around a model parameter from the expert. Instead, we relied on the more general approach to estimating uncertainty involved in catch reconstructions-an approach that was inspired by criteria used by the Intergovernmental Panel on Climate Change, as previously described (Mastrandrea et al., 2010; Table 2).
As with any research method, there are limitations to expert advice. Most notable is the range of subjective and psychological biases that experts, and indeed all humans, are prone to (see overview in Supporting Information of Martin et al., 2012). Given the above, we agree with the statement of Martin et al. (2012) that: "Expert knowledge should be regarded only as a snapshot of the expert's judgments in time, and expert assumptions and reasoning should be documented in such a way that they can be updated as new empirical knowledge accrues."

\section{Tourist demand for local fishes}

We separated tourist demand for local fishes into 2 categories: 1) demand by stopover visitors and 2) demand by visitors who arrived on cruise ships. For our study, we define stopover visitors as tourists that spend at least one night in The Bahamas (Cleare, 2007). Most stopover visitors arrive by air, but some of them arrive by other means (e.g., private yacht). Stopover visitors fish recreationally and consume local fishes in restaurants in The Bahamas. In contrast, tourists that arrive by cruise ship, as defined in our study, typically spend only a few hours ashore in The Bahamas and increase demand for local fishes only through seafood consumption during shore visits.

To estimate stopover visitor demand for local fishes through seafood consumption in hotel restaurants, we designed and successfully administered a local seafood consumption survey with 11 major hotels on 5 different island groups. Our study sample represented $37 \%$ of all hotel rooms in The Bahamas in 2010. Hotels in our survey ranged in size from 19 to 2932 rooms. In all instances, the purchasing manager or head chef of a hotel restaurant completed the survey, which included requests for information on the type, quantity, origin (i.e., The Bahamas versus imported), and dollar value of fishes supplied to the restaurant on a yearly basis (Smith and Zeller ${ }^{5}$ ).

In our survey, there was a suspiciously large quantity of seafood that was purported to be of local origin. We, therefore, assumed that $10 \%$ of all so-called local seafood was actually imported and we adjusted consumption accordingly. Visitors to The Bahamas consume both local and imported (e.g., salmon) seafood in hotel restaurants. Our study focused only on local seafood consumption. Overall seafood consumption (i.e., both local and imported products) by visitors to The Bahamas is therefore much greater than our estimates provided here.

Then we combined tourist data (e.g., hotel occupancy rates, number of visitor nights per year) with results from our survey to estimate a consumption rate per stopover visitor for consumption of local seafood. Although staff at hotels provided data for a period that ranged from 2 through 18 years, most hotels provided data for only the last 2 years of our time series (i.e., 2009-2010). We are unaware of any previous estimates of local seafood consumption rates in hotels in The 
Bahamas. Hence, we maintained the average consumption rate per stopover visitor for the years 2009-2010 based on our survey results (i.e., $0.49 \mathrm{~kg} \cdot$ visitor $^{-1} \cdot$ night $^{-1}$ and 1.08 $\mathrm{kg} \cdot$ visitor $^{-1} \cdot$ night $^{-1}$ for visitors to New Providence and Grand Bahama and to the Family Islands, respectively) for the remainder of the time series (i.e., 1950-2008), although this extrapolation may have resulted in a slight overestimate of local seafood consumption rates in the earliest parts of the time series (e.g., the 1950s).

Stopover visitors, by fishing recreationally, also increase local demand on fisheries resources (see the previous Recreational fishery section). However, because our tournament data did not distinguish between resident and tourist individuals that fish, we assumed that $98 \%$ of all tournament catch was taken by stopover visitors. The assumption that most tournament catch was taken by tourists is based on the fact that most sport fishing tournaments in The Bahamas are geared toward tourists (Thompson, 1989; Cleare, 2007) and on the notion that only a small percentage of the Bahamian resident population fishes for recreation (see the previous Recreational fishery section).

We are unaware of any estimates of local seafood consumption by visitors who arrive on cruise ships during their shore visits in The Bahamas. To be conservative, we assumed that, during $1950-2010,10 \%$ of all visitors from cruise ships consumed local seafood equivalent to 1 plate-size snapper during their visit (i.e., 0.31 $\mathrm{kg} \cdot$ visitor $^{-1}$.trip $^{-1}$ ).

\section{Results}

\section{Reconstructed total catch}

Reconstructed total catch from 1950 through 2010 was 884,500 t, a level that is 2.6 times the $336,190 \mathrm{t}$ reported by FAO for The Bahamas. Catches increased from around $2300 \mathrm{t} /$ year in 1950 to a peak of 24,700 t/year in 1985 and a second, smaller peak of 22,200 t/year occurred in 2003 , before declining to 18,600 t/year by 2010 (Fig. 3A). Notably, recreational fishing accounted for more than half of the reconstructed total catch over the full time period (i.e., $55 \%$ or 490,100 t), followed by the largescale, commercial Caribbean spiny lobster (29\%), arti-

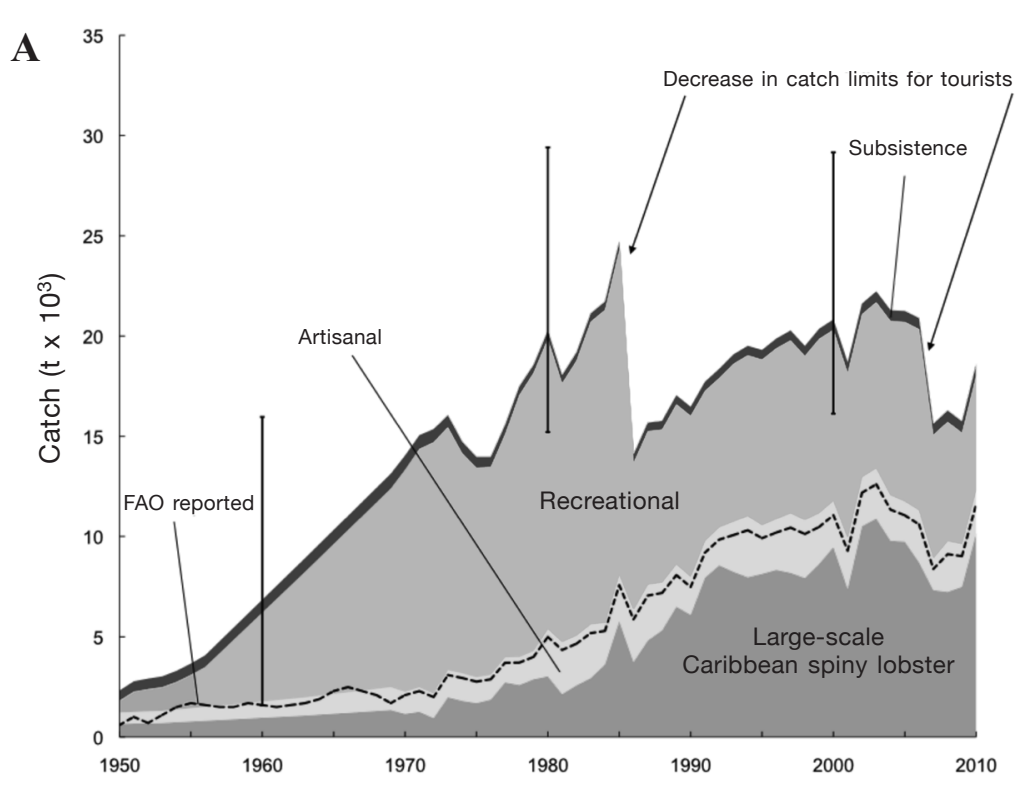

\section{B}

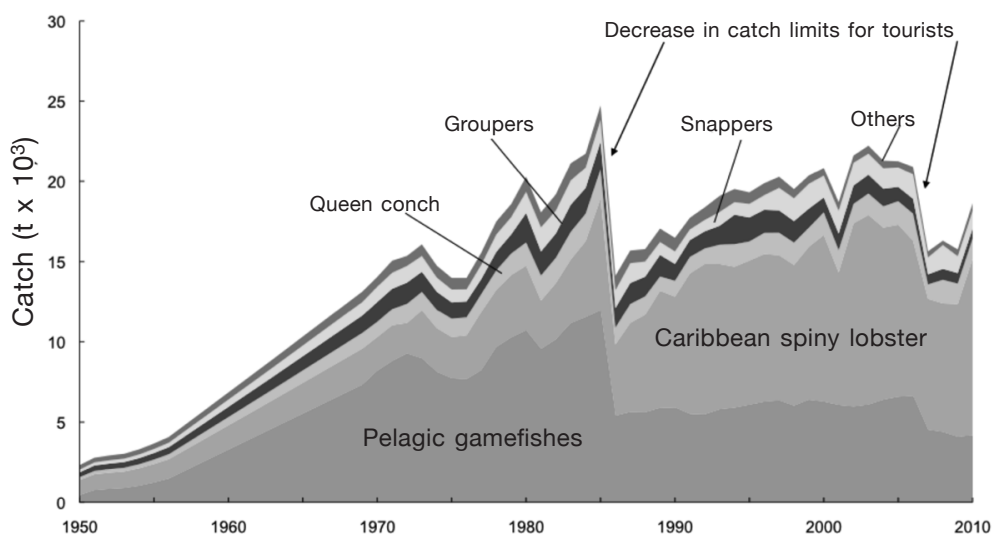

Figure 3

Reconstructed catch in metric tons ( $t$ ) for The Bahamas during 1950-2010 by (A) fisheries sector, where bars indicate ranges of uncertainty for 1960 (for the period 1950-1969), 1980 (for the period 1970-1989), and 2000 (for the period 1990-2010), and by (B) major taxa. In graph A, the dashed line represents official landings data reported to FAO, and the commercial sector is subdivided into the artisanal fishery and the large-scale fishery for Caribbean spiny lobster (Panulirus argus). For a list of species within each taxon shown in graph B, see Smith and Zeller. ${ }^{5}$ In both graphs, arrows indicate the period when changes were made in catch limit regulations for tourists engaged in recreational fishing. 


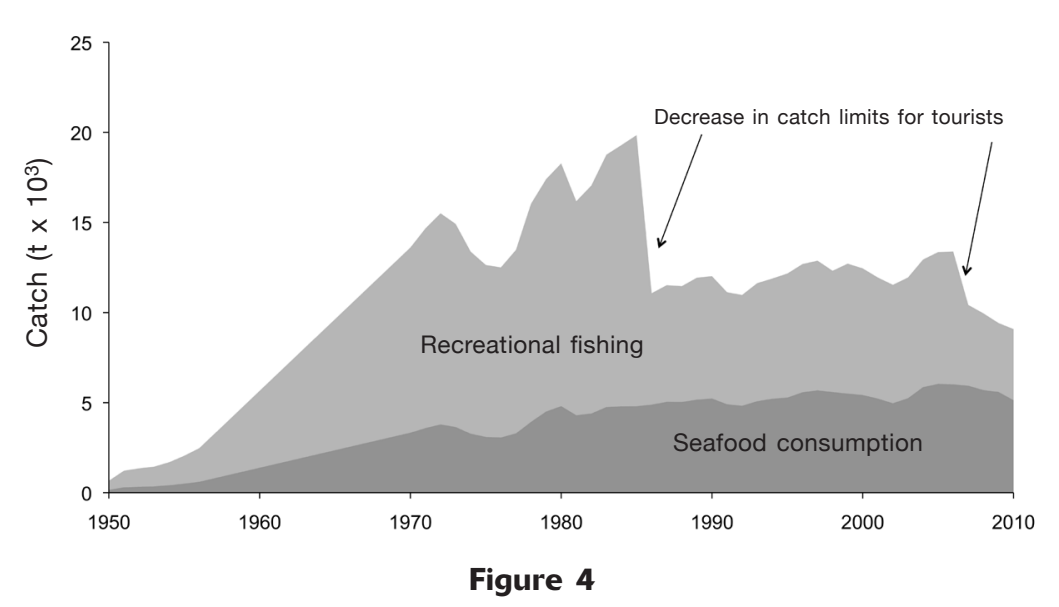

Demand for local fishes, measured as catch in metric tons ( $t$ ), driven by tourism by both stopover visitors and visitors who arrived by cruise ship in The Bahamas during 1950-2010. Arrows indicate periods when changes were made to regulations of catch limits for tourists engaged in recreational fishing.

\section{Recreational fishery}

Reconstructed recreational catch for the period 1950-2010 was 490,100 t; of this catch, less than 1\% (around $420 \mathrm{t}$ ) was attributed to major tournaments. Catch increased from 600 t/year in 1950 to a peak of around 16,100 t/year in 1985 , before declining rapidly to 7300 t/year in 1986 after the introduction of maximum catch limits for key taxa for visitors who fish recreationally. A second, but smaller peak occurred in 2006 at 9000 t/year before again declining sharply to just under 5700 t/ year in 2010 because of revisions made in 2007 to the recreational fishing regulations for visitors (Fig. 3A).

\section{Tourist demand for local fishes}

Tourist demand for local fishes (through recreational fishing and from hotel restaurants) from 1950 through marized in Fig. 3B). Pelagic gamefishes accounted for the greatest proportion of catch during 1950-2010 (41\%), followed closely by Caribbean spiny lobster (35\%), and queen conch, groupers, and snappers each accounted for less than $10 \%$ of total catch (Fig. 3B). Over the last decade (i.e., 2000-2010), however, catch of Caribbean spiny lobster (51\%) has surpassed catch of pelagic gamefishes $(29 \%)$.

\section{Commercial fishery}

Reconstructed total catch during 1950-2010 by the artisanal fishery totaled 103,800 t, increasing from 560 t/year in 1950 to a peak of 3060 t/year in 1994 before declining to just under 2180 t/year by 2010 (Fig. 3A). In contrast, catch of the large-scale fishery for Caribbean spiny lobster during 1950-2010 totaled 257,400 t, accounting for $71 \%$ of reconstructed total commercial catch (i.e., catch from both the artisanal fishery and the large-scale fishery for Caribbean spiny lobster). Large-scale commercial catch of Caribbean spiny lobster increased from just under 660 t/year in 1950 to a peak of nearly 10,900 t/year in 2003, before declining slightly to 10,200 t/year in 2010 (Fig. 3A).

\section{Subsistence fishery}

Reconstructed subsistence catch totaled nearly 33,100 t during 1950-2010, increasing from 500 t/year in 1950 to a peak of around $740 \mathrm{t} /$ year in the late $1960 \mathrm{~s}$, before declining to 590 t/year in 2010 (Fig. 3A). The majority of catch $(69 \%)$ was taken by residents of the Family Islands, despite the size of the population of residents there being $75 \%$ smaller than that of the resident population on the more developed islands of New Providence and Grand Bahama.
2010 totaled $661,800 \mathrm{t}$, accounting for $75 \%$ of reconstructed total catches in the entire country (Fig. 4). The total number of visitors to The Bahamas each year is in the millions, and visitors have outnumbered the resident population by an order of magnitude for nearly half a century (Fig. 1). It is, therefore, not surprising that tourism has such a sizeable effect on fisheries removals in The Bahamas. Demand increased from 660 t/year in 1950 to a peak of more than 19,800 t/year in 1985 before declining to 9100 t/year in 2010 (Fig. 4). Almost two-thirds of this demand $(435,900 \mathrm{t})$ was driven by recreational fishing by stopover visitors, and the remainder was a result of seafood consumption by stopover visitors (34\%) and by visitors from cruise ships (0.3\%) (Fig. 4). Although there were $13 \%$ more visitors from cruise ships than stopover visitors during 1950-2010, it is not surprising that less than $1 \%$ of demand was attributed to visitors who arrived by cruise ship, given that only a small fraction of them consumed local seafood and that none fished recreationally during their stay.

\section{Discussion}

Reconstructed total catches were 2.6 times the landings reported by the FAO for The Bahamas. The magnitude of the discrepancy between our reconstructed estimate and officially reported statistics is comparable to results from reconstruction studies of the fisheries of other small island nations, findings that ranged from a 1.2-fold difference in the case of the Azores (1950-2010; Pham et al., 2013) to an average 2.5-fold difference for 25 Pacific island countries and territories (Zeller et al., 2015).

In our study, the source of discrepancy for The Bahamas was twofold. First, only commercial landings 
are accounted for in official statistics, a practice that is common in many countries as a result of the historic focus on commercial landings for economic development purposes (Ward, 2004). The lack of reporting on noncommercial sectors is justified currently by real or perceived costs and difficulties associated with quantifying spatially dispersed fisheries (Zeller et al., 2007, 2015). Even official, commercial landings statistics for The Bahamas are deficient and known to be underreported by up to $15 \%$ per year for some taxa (Table 4). The second and more important cause of discrepancy is that catches by the recreational and subsistence fisheries are substantial and missing entirely in national statistics, accounting for roughly $55 \%$ and $4 \%$ of reconstructed total catch during 1950-2010, respectively (Fig. 3A). These unreported, noncommercial sectors, therefore, represent major sources of impact on species and stocks of marine resources that would never be accounted for if one considers only official data.

Another major discrepancy between our reconstructed estimate and official data is the year in which fisheries catches peaked. According to our reconstruction, total catches peaked in the mid-1980s, not in 2003 as indicated by FAO national data (Fig. 3A). The peak in reconstructed catches was driven by recreational fishing in which, before 1986, no maximum allowable catch legislation existed for tourists. The primary reason for this legislation was that, before 1986, tourists were thought to be removing large quantities of fish from the waters of The Bahamas by essentially engaging in commercial fishing "under the guise of sport fishing" (Thompson, 1989). Our reconstruction indicates that a second peak in fisheries catches did in fact occur in 2003 , but at more than 22,200 t/year- as opposed to 12,610 t/year (Fig. 3A). This second peak was driven by increased catches in the large-scale commercial fishery for Caribbean spiny lobster, where the annual catch totaled nearly 11,000 $t$ in 2003. The fact that the general trend in the reconstruction for The Bahamas differs somewhat from the trend that was based on officially reported statistics is common among reconstruction studies. For example, the synthesis of reconstructions for 25 Pacific island countries and territories showed that there was a distinct and significant difference in the time-series trends between reported and reconstructed catches (Zeller et al., 2015).

The fact that, in 1986 and again in 2007, the government of The Bahamas introduced maximum recreational catch limits for key taxa for tourists indicates that even in the absence of quantitative catch statistics, there was (and remains) a local perception that catches from this sector are substantial and in need of regulation (Braynen ${ }^{6}$ ). Indeed, the magnitude of estimated recreational catches from 1950 through 2010 is astounding ( $55 \%$ of total reconstructed catch), equating to 1.4 times the commercial catch over the same period. Although recreational catches can exceed commercial landings for some marine fish populations (e.g., see Schroeder and Love, 2002; Coleman et al., 2004), it is rare for recreational catches to dominate reconstructed estimates, as they do for The Bahamas. In comparison, recreational catches accounted for only $3 \%$ and $25 \%$ of total removals in reconstruction studies of marine fisheries in the Baltic Sea (1950-2007; Zeller et al., 2011b) and the Azores (1950-2010; Pham et al., 2013), respectively. Yet, despite their significance, recreational catches remain unaccounted for in The Bahamas, as in most other parts of the world, but Freire et al. (in press) is using the reconstruction process to estimate catches from marine recreational fisheries for 126 countries and territories.

Our findings debunk the notion, at least for The Bahamas, that catches from recreational fisheries are generally relatively small and, therefore, negligible when compared with the catches from other major sectors. McClenachan (2013) makes a similar point for the Florida Keys, where recreational fishing, driven primarily by the tourist industry, has contributed to the decline of vulnerable nearshore fishes. Indeed, our findings take on added importance as evidence accumulates regarding the role of recreational fishing in the exploitation of fish populations that require conservation (Coleman et al., 2004; Cooke and Cowx, 2004; Shiffman et al., 2014).

The magnitude of the impact of tourism on fisheries removals is a concern. A major issue is the open access nature of recreational fishing, for which managers regulate per capita maximum allowable catch (at least in principle) but have no control over the number of visitors that fish recreationally (Coleman et al., 2004). Because, as we have noted previously, total visitors now outnumber resident populations in many small island states and territories in the wider Caribbean, including those in The Bahamas (Table 1), trends in tourist demand for local fish (through recreational fishing and seafood consumption in local hotels) are similar across the Caribbean. Incomplete or missing reports of fisheries removals by the tourist industry can lead to inadequate fisheries management, creating a situation in which continued population growth and rising fisheries demands by residents and tourists could place unsustainable pressures on fisheries resources.

Numerous studies of the reconstruction of catch time series have revealed that official landings data for most countries are incomplete (e.g., Zeller et al., 2006, 2007; Wielgus et al., 2010; Zeller at al., 2011a, 2011b; Le Manach et al., 2012; Belhabib et al., 2014; Zeller et al., 2015). The results of this study clearly illustrate that The Bahamas can be added to the growing list of countries with inadequate reporting and highlight the rare situation that recreational fishing (primarily driven by the tourist industry) dominates reconstructed total catches. This rare situation is worrisome because of its obvious implications for effective conservation and resource management, particularly in light of the dual fisheries demands by a burgeoning tourist industry and a growing resident population. 


\section{Acknowledgments}

We thank The Bahamas Department of Marine Resources, particularly M. Braynen for data, for expert opinion, and helpful discussions. We also thank The Bahamas Ministry of Tourism, particularly G. Delancy, for data. Data provided by A. Venizelos from the NOAA Southeast Fisheries Science Center are also greatly appreciated. DZ acknowledges the support of the Sea Around Us, funded by The Pew Charitable Trusts and The Paul G. Allen Family Foundation.

\section{Literature cited}

Belhabib, D., V. Koutob, A. Sall, V. W. Y. Lam, and D. Pauly. 2014. Fisheries catch misreporting and its implications: the case of Senegal. Fish. Res. 151:1-11. Article

Bentley, N., and K. Stokes.

2009. Contrasting paradigms for fisheries management decision making: how well do they serve data-poor fisheries? Mar. Coast. Fish. 1:391-401. Article

Burgman, M., A. Carr, L. Godden, R. Gregory, M. McBride, L. Flander, and L. Maguire.

2011. Redefining expertise and improving ecological judgment. Conserv. Lett. 4:81-87. Article

Cleare, A. B.

2007. History of tourism in The Bahamas: a global perspective, 633 p. Xlibris, Bloomington, IN.

Coleman, F. C., W. F. Figueira, J. S. Ueland, and L. B. Crowder. 2004. The impact of United States recreational fisheries on marine fish populations. Science 305:1958-1960. Article

Cooke, S. J., and I. G. Cowx.

2004. The role of recreational fishing in global fish crises. BioScience 54:857-859.

Covey, C.

2000. Beware the elegance of the number zero. Clim. Chang. 44:409-411. Article

Cox, L., J. L. Hammerton, and N. Wilchcombe (eds.).

2005. GEO Bahamas 2005: The Bahamas state of the environment report, 62 p. United Nations Environment Program, Global Environment Outlook. Bahamas Environment, Science, and Technology (BEST) Commission, Nassau, Bahamas. [Available at website.]

Crome, F. H. J., M. R. Thomas, and L. A. Moore.

1996. A novel Bayesian approach to assessing impacts of rain forest logging. Ecol. Appl. 6:1104-1123. Article

Diaz, G. A., M. Ortiz, and E. D. Prince.

2007. Updated white marlin (Tetrapturus albidus) and blue marlin (Makaira nigricans) catch rates from the U.S. recreational tournament fishery in the northwest Atlantic, U.S. Gulf of Mexico, Bahamas and U.S. Caribbean 1973-2005. Collect. Vol. Sci. Pap. ICAAT 60:1678-1695.

Field, J., J. Cope, and M. Key.

2010. A descriptive example of applying vulnerability evaluation criteria to California nearshore species. In Managing data-poor fisheries: case studies, models and solutions; Berkeley, CA, 1-4 December 2008 (R. M. Starr, C. S. Culver, C. Pomeroy, S. McMillan, T. Barnes, and D. Aseltine-Neilson, eds.), p. 235-246. [Available in CD-ROM from California Sea Grant, 9500 Gilman Dr., \#0232, La Jolla, CA 92093-0232.]
Freire, K., D. Belhabib, B. Doherty, K. Kleisner, V. Lam, J. Mendonca, P. Moro, F. Motta, M. L. D. Palomares, D. Pauly, N. Smith, A. McCrea Strub, L. Teh, D. Zeller, and K. Zylich. In press. Estimating global catches from marine recreational fisheries. FAO Tech. Rep. FAO, Rome.

Griffiths, S. P., P. M. Kuhnert, W. N. Venables, and S. J. M. Blaber.

2007. Estimating abundance of pelagic fishes using gillnet catch data in data-limited fisheries: a Bayesian approach. Can. J. Fish. Aquat. Sci. 64:1019-1033. Article

Honey, K. T., J. H. Moxley, and R. M. Fujita.

2010. From rags to fishes: data-poor methods for fishery managers. In Managing data-poor fisheries: case studies, models and solutions; Berkeley, CA, 1-4 December 2008 (R. M. Starr, C. S. Culver, C. Pomeroy, S. McMillan, T. Barnes, and D. Aseltine-Neilson, eds.), p.159 184. [Available as CD-ROM from California Sea Grant, 9500 Gilman Dr., \#0232, La Jolla, CA 92093-0232.]

Johannes, R. E.

1998. The case for data-less marine resource management: examples from tropical nearshore finfisheries. Trends Ecol. Evol. 13:243-246. Article

Kuhnert, P. M.

2011. Four case studies in using expert opinion to inform priors. Environmetrics 22:662-674. Article

Le Manach, F., C. Gough, A. Harris, F. Humber, S. Harper, and D. Zeller.

2012. Unreported fishing, hungry people and political turmoil: the recipe for a food security crisis in Madagascar? Mar. Policy 36:218-225. Article

MacCall, A. D.

2009. Depletion-corrected average catch: a simple formula for estimating sustainable yields in data-poor situations. ICES J. Mar. Sci. 66:2267-2271. Article

Maitland, T. E.

2006. Dietary habits, diversity and the indigenous diet of the Turks and Caicos Islands: implications for islandspecific nutrition intervention. West Indian Med. J. 55:1-13.

Manly, B. F. J., and D. Mackenzie.

2000. A cumulative sum type of method for environmental monitoring. Environmetrics 11:151-166. Article

Martin, T. G., M. A. Burgman, F. Fidler, P. M. Kuhnert, S. LowChoy, M. McBride, and K. Mengersen.

2012. Eliciting expert knowledge in conservation science. Conserv. Biol. 26:29-38. Article

Mastrandrea, M. D., C. B. Field, T. F. Stocker, O. Edenhofer, K. L. Ebi, D. J. Frame, H. Held, E. Kriegler, K. J. Mach, P. R. Matschoss, G.-K. Plattner, G. W. Yohe, and F. W. Zwiers. 2010. Guidance note for lead authors of the IPCC fifth assessment report on consistent treatment of uncertainties, 4 p. Intergovernmental Panel on Climate Change (IPCC), Geneva, Switzerland. [Available at website.]

McClenachan, L.

2013. Recreation and the "Right to Fish" movement: anglers and ecological degradation in the Florida Keys. Environ. Hist. 18:76-87. Article

Morgan, M. G., L. F. Pitelka, and E. Shevliakova.

2001. Elicitation of expert judgments of climate change impacts on forest ecosystems. Clim. Chang. 49:279-307. Article

Murray, J. V., A. W. Goldizen, R. A. O’Leary, C. A. McAlpine, H. P. Possingham, and S. L. Choy

2009. How useful is expert opinion for predicting the distribution of a species within and beyond the region of 
expertise? A case study using brush-tailed rock wallabies Petrogale penicillata. J. Appl. Ecol. 46:842-851. Article Pauly, D.

1998. Rationale for reconstructing catch time series. Bull. EC Fish. Coop. 11(2):4-7.

Pham, C. K., A. Canha, H. Diogo, J. G. Pereira, R. Prieto, and T. Morato.

2013. Total marine fishery catch for the Azores (19502010). ICES J. Mar. Sci. 70:564-577. Article

Schroeder, D. M., and M. S. Love.

2002. Recreational fishing and marine fish populations in California. CalCOFI Rep. 43:182-190.

Shiffman, D. S., A. J. Gallagher, J. Wester, C. C. Macdonald, A. D. Thaler, S. J. Cooke, and N. Hammerschlag.

2014. Trophy fishing for species threatened with extinction: a way forward building on a history of conservation. Mar. Policy 50:318-322. Article

Smith, D., A. Punt, N. Dowling, A. Smith, G. Tuck, and I. Knuckey.

2009. Reconciling approaches to the assessment and management of data-poor species and fisheries with Australia's harvest strategy policy. Mar. Coast. Fish. 1:244-254. Article

Thompson, R. W.

1989. Marine recreational fishing in the Bahamas-a case study. Proc. Gulf Caribb. Fish. Inst. 39:75-85.

UNWTO (World Trade Organization).

2014a. UNTWO tourism highlights: 2014 edition, 14 p. World Tourism Organization, Madrid, Spain. [Available Article.] 2014b. Tourism in small island developing states (SIDS): building a more sustainable future for the people of islands, 5 p. World Tourism Organization. [Available at website.]

Ward, M.

2004. Quantifying the world: UN ideas and statistics, 352 p. Indiana Univ. Press, Bloomington, IL.

Wielgus, J., D. Zeller, D. Caicedo-Herrera, and U. R. Sumaila. 2010. Estimation of fisheries removals and primary economic impact of the small-scale and industrial marine fisheries in Colombia. Mar. Policy 34:506-513. Article

Zeller, D., S. Booth, P. Craig, and D. Pauly.

2006. Reconstruction of coral reef fisheries catches in American Samoa, 1950-2002. Coral Reefs 25:144-152. Article

Zeller, D., S. Booth, G. Davis, and D. Pauly.

2007. Re-estimation of small-scale fishery catches for U.S. flag-associated island areas in the western Pacific: the last 50 years. Fish. Bull. 105:266-277.

Zeller, D., S. Booth, E. Pakhomov, W. Swartz, and D. Pauly. 2011a. Arctic fisheries catches in Russia, USA, and Canada: baselines for neglected ecosystems. Polar Biol. 34:955-973. Article

Zeller, D., P. Rossing, S. Harper, L. Persson, S. Booth, and D. Pauly.

2011b. The Baltic Sea: estimates of total fisheries removals 1950-2007. Fish. Res. 108:356-363. Article

Zeller, D., S. Harper, K. Zylich, and D. Pauly

2015. Synthesis of underreported small-scale fisheries catch in Pacific island waters. Coral Reefs 34:25-39. Article 